\title{
Identification the Need of Electronic-Based Physics Teaching Materials for Increasing Problem Solving Ability in the 21st Century
}

\author{
Lis Tyas, Harjana, Daru Wahyuningsih \\ Magister Pendidikan Fisika, Fakultas Pascasarjana, Universitas Sebelas Maret, Surakarta, Indonesia \\ *Corresponding Authors : listyas.tyas@gmailcom
}

\begin{abstract}
This study aims to identify and describe the need for physics teaching materials in the 21st century to increase problem-solving abilities in high school students. The research sample in this study were students of class X SMA Al Islam 1 Surakarta. Data analysis was carried out descriptively, the data obtained in this study were data from interviews, questionnaires, student learning outcomes on Business and Energy material. The results of this study indicate that students need teaching materials in the form of learning media that support the 21st century equipped with a learning model that can improve students' ability to solve problems, namely E-module STEM-PjBL-based.
\end{abstract}

Keywords: Teaching materials, E-Modul, STEM-PjBL, Problem Solving

\begin{abstract}
Abstrak: Penelitian ini bertujuan untuk mengidentifikasi dan mendiskripsikan kebutuhan bahan ajar fisika di abad 21 terhadap peningkatan kemampuan pemecahan masalah pada siswa Sekolah Menengah Atas. Sampel penelitian dalam penelitian ini yaitu siswa kelas X SMA Al Islam 1 Surakarta. Analisis data dilakukan secara dekriptif, data yang diperoleh dalam penelitian ini berupa data hasil wawancara, angket, hasil belajar siswa pada materi Usaha dan Energi. Hasil dari penelitian ini yaitu siswa membutuhkan bahan ajar berupa media pembelajaran yang mendukung abad 21 dilengkapi dengan model pembelajaran yang dapat meningkatkan kemampuan siswa dalam memecahkan masalah yaitu Emodul berbasis STEM-PjBL
\end{abstract}

Kata Kunci : Bahan ajar, E-Modul, STEM-PjBL, Pemecahan masalah

\section{PENDAHULUAN}

Perkembangan Abad ke-21 ditandai sebagai abad keterbukaan atau abad globalisasi, kehidupan manusia mengalami perubahan tata kehidupan dalam abad sebelumnya. Abad ke-21 membutuhkan sumber daya manusia berkualitas yang dihasilkan oleh lembaga-lembaga yang dikelola secara profesional sehingga membuahkan hasil unggulan. Salah satu upaya yang dilakukan untuk memberdayakan sumber daya manusia yang berkualitas yaitu upaya dari lembaga dalam bidang pendidikan. Pendidikan saat ini diharapkan dapat menghasilkan SDM yang memiliki kemampuan komunikasi dan kolaborasi yang kuat, ahli dalam menggunakan teknologi, keterampilan berpikir kreatif dan inovatif serta kemampuan untuk memecahkan masalah [1].

Kemdikbud merumuskan bahwa paradigma pembelajaran abad 21 menekankan pada kemampuan peserta didik dalam mencari tahu dari berbagai sumber, merumuskan permasalahan, berpikir analitis dan kerjasama serta berkolaborasi dalam menyelesaikan masalah[2]. Adapun penjelasan mengenai framework pembelajaran abad ke-21 menurut Badan Standar Nasional Pendidikan adalah: (a) Kemampuan berpikir kritis dan pemecahan masalah (Critical-Thinking and Problem-Solving Skills), mampu berfikir secara kritis, lateral, dan sistemik, terutama dalam konteks pemecahan masalah; (b) Kemampuan berkomunikasi dan bekerjasama (Communication and Collaboration Skills), mampu berkomunikasi dan berkolaborasi secara efektif dengan berbagai pihak; (c) Kemampuan mencipta dan membaharui 
(Creativity and Innovation Skills), mampu mengembangkan kreativitas yang dimilikinya untuk menghasilkan berbagai terobosan yang inovatif; (d) Literasi teknologi informasi dan komunikasi (Information and Communications Technology Literacy), mampu memanfaatkan teknologi informasi dan komunikasi untuk meningkatkan kinerja dan aktivitas sehari-hari; (e) Kemampuan belajar kontekstual (Contextual Learning Skills), mampu menjalani aktivitas pembelajaran mandiri yang kontekstual sebagai bagian dari pengembangan pribadi, dan (f) Kemampuan informasi dan literasi media, mampu memahami dan menggunakan berbagai media komunikasi untuk menyampaikan beragam gagasan dan melaksanakan aktivitas kolaborasi serta interaksi dengan beragam pihak.[3] Pembelajaran abad 21 diarahkan pada model pembelajaran yang mendorong siswa mencari tahu dari berbagai sumber observasi, bukan sekedar diberitahu. Pembelajaran juga diarahkan untuk membiasakan siswa mampu merumuskan masalah, bukan hanya menyelesaikan masalah serta melatih berpikir kritis bukan berpikir mekanistis. Kerjasama dan kolaborasi juga ditekankan dalam menyelesaikan masalah dalam proses pembelajaran [4]

Salah satu upaya yang ditempuh pemerintah untuk meningkatkan kualitas pendidikan adalah melalui pengembangan bahan ajar [5]. Bahan ajar perlu dikembangkan karena merupakan salah satu upaya yang dapat membantu guru menyampaikan materi dalam proses pembelajaran. Bahan ajar yang menunjang terlaksananya paradigma pembelajaran abad 21 dihubungkan dengan perkembangan di bidang teknologi. Bahan ajar berbasis teknologi dapat membuat siswa beradaptasi dengan arus perkembangan di bidang IT. Siswa yang terbiasa menggunakan media bahan ajar berbasis IT secara tidak langsung juga mengembangkan kemampuannya pada bidang tersebut dan dapat mengembangkan kualitas SDM yang dimiliki. Peraturan Pemerintah Nomor 17 tahun 2010 pasal 48 dan 59 mengisyaratkan dikembangkannya sistem informasi pendidikan yang berbasis teknologi dan informasi.

Hasil penelitian oleh Taufik Solihudin [6] menyatakan bahwa pengembangan E-Modul berbasis Web dapat meningkatkan pencapaian kompetensi pengetahuan peserta didik. Hasil penelitian oleh Fengky Adie Perdana [7] menyatakan bahwa motivasi siswa menggunakan modul elektronik Fisika berbasis ketrampilan proses siswa lebih baik daripada pembelajaran konvensional. Hasil penelitian oleh Komang Redy Winatha [8] menyimpulkan bahwa pembelajaran simulasi digital dengan menggunakan e-module interaktif berbasis proyek dapat meningkatkan prestasi siswa. Hasil penelitian Syamsurizal [9] dalam penelitiannya yang berjudul menyatakan bahwa e-modul memiliki tampilan yang menarik, mudah dipahami dan mudah digunakan.

Berdasarkan paparan tersebut maka tujuan dari penelitian ini adalah mengidentifikasi dan mendiskripsikan kebutuhan bahan ajar fisika berbasis elektronik untuk meningkatkan kemampuan pemecahan masalah di abad ke-21."

\section{METODE PENELITIAN}

Penelitian ini merupakan penelitian deskriptif pada identifikasi kebutuhan bahan ajar fisika berbasis elektronik untuk meningkatkan kemampuan pemecahan masalah di abad ke-21. Pendekatan deskriptif berfungsi untuk mendeskripsikan atau memberi gambaran terhadap objek yang diteliti melalui data atau sampel yang telah terkumpul sebagaimana adanya (Sugiyono,2013). Populasi dari penelitian ini adalah siswa kelas X SMA Al Islam 1 Surakarta tahun ajaran 2019/2020. Instrumen pada penelitian ini adalah instrumen angket dan instrumen wawancara. Metode pengumpulan data menggunakan metode wawancara, angket, dan kajian dokumen yang berkaitan dengan pembelajaran Fisika. Sedangkan analisis data kualitatif meliputi: (1)reduksi data, (2) penyajian data, (3) verifikasi/penarikan kesimpulan. 


\section{HASIL DAN PEMBAHASAN}

Tahap dalam melakukan penelitian diskriptif adalah pengumpulan informasi. Hasil dari tahap penelitian dan pengumpulan informasi adalah sebagai berikut.

\subsection{Hasil Analisis Daya serap Ujian Nasional}

Analisis terhadap daya serap ujian nasional bertujuan untuk mengetahui bahwa materi usaha dan energi masih memiliki pencapaian yang rendah dan memungkinkan untuk ditindaklanjuti. Analisis daya serap ujian nasional ini dilakukan pada data Pamer Ujian Nasional oleh Badan Standar Nasional Pendidikan (BSNP) pada tahun pelajaran 2015/2016, 2016/2017, dan 2017/2018. Setiap indikator materi usaha dan energi terwakilkan oleh satu soal. Menurut aspek kognitif proses, terdapat satu soal UN pada tahun pelajaran 2015/2016 dan satu soal tahun pelajaran 2016/2017 termasuk dalam kategori mengaplikasikan (C3) sedangkan soal UN pada tahun pelajaran 2017/2018 terdapat satu soal termasuk kategori memahami (C2) dan empat soal termasuk dalam kategori mengaplikasikan (C3). Berdasarkan data tersebut menunjukkan bahwa dalam penyelesaian soal membutuhkan kemampuan pemecahan masalah berhubung dengan pengaplikasian persamaan dan konsep dari materi.

Hasil analisis data dari hasil daya serap Ujian Nasional (UN) selama tiga tahun berturut-turut yaitu tahun ajaran 2015/2016, 2016/2017, 2017/2018 menyatakan bahwa di kota Surakarta memperoleh presentase tingkat kota untuk penguasaan materi usaha dan energi adalah 58,25\% , 62,97\%, dan 53,74\%. Presentase tingkat provinsi adalah 50,94\%, 51,78\%, dan 46,17\% . Presentasi tingkat nasional 52,17\%, 47,35\%, dan 44,22\%. Hasil analisis hasil ujian nasional fisika ada materi usaha dan energi di SMA AL Islam 1 Surakarta pada tingkat sekolah, $\mathrm{kota} / \mathrm{kab}$, provinsi, dan nasional menunjukkan pencapaian daya serap UN beberapa indikator masih rendah. Hal ini ditunjukkan pada satu indikator pada UN tahun 2015/2016 dengan pencapaian pada tingkat sekolah sebesar $61,59 \%$, tingkat kabupaten sebesar 60,87\%, tingkat provinsi sebesar $61,37 \%$, dan tingkat nasional sebesar $57,80 \%$. Satu indikator pada UN tahun 2016/2017 dengan pencapaian pada tingkat sekolah sebesar 48,00 \%, tingkat kabupaten sebesar $64,74 \%$, tingkat provinsi sebesar 57,58 \%, dan tingkat nasional sebesar 55,69 \%. Lima indikator pada UN tahun 2017/2018 dengan pencapaian pada tingkat sekolah rata-rata 50,22\%, tingkat kabupaten rata-rata $53,75 \%$, tingkat provinsi rata-rata $46,17 \%$, dan pada tingkat nasional rata-rata $44.22 \%$.

\subsection{Hasil Analisis Hasil Penilaian Akhir Tahun}

Hasil analisis terhadap data penilaian akhir tahun ajaran 2019/2020 menunjukkan bahwa materi usaha dan energi, siswa memiliki ketuntasan masih rendah dan memungkinkan untuk ditindaklanjuti. Rendahnya hasil penilaian akhir tahun ada materi usaha dan energi ditunjukkan dengan item 18 dengan pencapaian $26 \%$, item 19 dengan pencapaian $40 \%$, item 20 dengan pencapaian $49 \%$, item 21 dengan pencapaian $36 \%$, item 22 dengan pencapaian $27 \%$, item 23 dengan pencapaian $53 \%$, item 24 dengan pencapaian $23 \%$, item 25 dengan pencapaian $54 \%$.

\subsection{Hasil Wawancara dengan Guru dan Siswa}

Hasil wawancara dengan guru dan siswa bertujuan untuk mengetahui tanggapan guru dan siswa terhadap bahan ajar dan proses pembelajaran fisika yang terdapat di sekolah. Hasil wawancara dengan guru menunjukkan bahwa proses pembelajaran fisika dengan baik sesuai tuntutan kurikulum 2013 yang menggunakan pendekatan langsung dan kontekstual dimana pendekatan yang melibatkan aplikasi di kehidupan sehari-hari. Selain itu guru juga menggunakan metode ceramah, tanya jawab dan diskusi. Sumber belajar dan bahan ajar yang digunakan oleh guru adalah buku pegangan dan LKS yang telah melalui seleksi sesuai 
kebutuhan. Penggunaan modul dan emodul belum optimal dikarenakan guru tidak membuat modul dan kurangnya motivasi dalam lingkup MGMP untuk membuat modul. Guru menyetujui apabila bahan ajar dapat disusun untuk meningkatkan kemampuan pemecahan masalah siswa selain itu proses belajar mengajar lebih variatif dalam menggunakan bahan ajar agar tidak monoton. Sementara itu, hasil wawancara dengan siswa menunjukkan bahwa siswa memerlukan bahan ajar yang menarik dan mudah digunakan dalam mempelajari konsep fisika.

\subsection{Hasil Angket Kebutuhan Siswa dan Guru}

Analisis kebutuhan siswa dan guru dilakukan dengan angket untuk memperoleh data tentang apa yang dibutuhkan guru dan siswa dalam pembelajaran fisika berdasarkan proses yang telah dilakukan selama pembelajaran. Hasil angket kebutuhan guru dan siswa menunjukkan bahwa guru telah menggunakan berbagai pendekatan dan model pembelajaran yang variatif, tetapi belum ada bahan ajar berupa e-modul yang mendukung kegiatan proses belajar mengajar. Siswa membutuhkan bahan ajar yang lebih variatif dan menarik dengan kombinasi gambar, video, dan tulisan. Selain itu, siswa belum sering menggunakan bahan ajar emodul

Pembelajaran Fisika mengalami tantangan tersendiri untuk dapat menjadi pelajaran yang mampu memberikan pemahaman kepada siswa tentang alam sekitar namun tetap dilakukan melalui proses belajar yang aktif dan menyenangkan. Belajar Fisika bukan hanya sekedar menghafal dan bukan pula sekedar mengingat rumus-rumus tanpa mengetahui kapan pemakaiannya, tetapi dibutuhkan pengertian, pemahaman akan suatu persoalan dalam Fisika. Siswa dituntut untuk dapat mengaitkan informasi baru dengan konsep-konsep yang sesuai dengan apa yang telah dimilikinya. Oleh karena itu, belajar Fisika harus ditampilkan dalam bentuk produk ilmiah, proses ilmiah, dan sikap ilmiah. Berdasarkan ketiga hal tersebut maka dalam mempelajari Fisika, siswa hendaknya diberi kesempatan untuk membuktikan kebenaran dari teori yang ada dan diberi kesempatan untuk menemukan sesuatu yang baru.

STEM merupakan pendekatan pembelajaran yang menghubungkan empat bidang yaitu sains, teknologi, engineering, dan matematika menjadi satu kesatuan yang holistik. Tujuan STEM dalam dunia pendidikan sejalan dengan tuntutan pendidikan abad 21, yaitu agar peserta didik memiliki literasi sains dan teknologi nampak dari membaca, menulis, mengamati, serta melakukan sains, serta mampu mengembangkan kompetensi yang telah dimilikinya untuk diterapkan dalam menghadapi permasalahan dalam kehidupan sehari-hari yang terkait bidang ilmu STEM[10]

Pembelajaran Fisika yang sesuai dengan pendekatan STEM dapat dilakukan dengan model pembelajaran PjBL (Project Based Learning). Model pembelajaran PjBL menekankan belajar kontekstual melalui kegiatan-kegiatan yang kompleks seperti memberi kebebasan pada siswa untuk bereksplorasi merencanakan aktivitas belajar, melaksanakan proyek secara kolaboratif, dan pada akhirnya menghasilkan suatu hasil produk[11]. Pembelajaran PjBL berpendekatan STEM merupakan pembelajaran berbasis projek dengan mengintegrasikan bidang-bidang STEM. Fisika memerlukan matematika sebagai alat dalam mengolah data, sedangkan teknologi dan teknik merupakan aplikasi dari Fisika. Beberapa manfaat dari pendekatan STEM membuat siswa mampu memecahkan masalah menjadi lebih baik, inovatif, mandiri, berpikiran logis, dan literasi teknologi [12]

\section{KESIMPULAN DAN SARAN}

Berdasarkan hasil penelitian yang dilakukan di SMA Al Islam 1 Surakarta, diperoleh bahwa bahan ajar yang dibutuhkan pada pembelajaran abad 21 adalah bahan ajar berbasis teknologi yaitu E-modul. Selain itu bahan ajar yang dapat meningkatkan kemampuan pemecahan masalah siswa adalah bahan ajar dengan pendekatan STEM (Science, Technology, engeneering, and 
Mathematic) dan dapat dilakukan dengan model pembelajaran PjBL (Project Based Learning). Oleh karena itu dapat disimpulkan bahwa siswa membutuhkan bahan ajar berupa media pembelajaran yang mendukung di abad 21 dilengkapi dengan model pembelajaran yang dapat meningkatkan kemampuan siswa dalam memecahkan masalah yaitu E-modul berbasis STEMPjBL

Saran yang dapat diberikan untuk penelitian-penelitian selanjutnya adalah pengembangan bahan ajar berbasis elektronik dengan pendekatan STEM dan model pembelajaran Project Based Learning (PjBL) untuk meningkatkan kemampuan siswa dalam memecahan masalah.

\section{DAFTAR PUSTAKA}

Miller, L. C., \& Northern, T. (2011). 21st Century skills: prepare student for the future. Kappa elta Pi Record.121-123.

Litbang Kemdikbud. 2013. Kurikulum 2013: Pergeseran Paradigma Belajar Abad-21. Retrieved September 29, 2015, from http://litbang.kemdikbud.go.id/index.php/indexberita-kurikulum/243-kurikulum-2013-pergeseran-paradigma-belajar-abad-21

BSNP. 2010. Paradigma Pendidikan Nasional Abad XXI. Badan Standar Nasional Pendidikan

Husamah dan Setyaningrum,Yanur .2013. Desain Pembelajaran Berbasis Pencapaian Kompetensi.Jakarta:Prestasi Pustakakarya

Bappenas. 2009. Rencana Kerja Pemerintah 2009. Jakarta: Kementerian Perencanaan Pembangunan Nasional

Solihudin, T.2018. Pengembangan E-Modul Berbasis Web Untuk Meningkatkan Pencapaian Kompetensi Pengetahuan Fisika Pada Materi Listrik Statis Dan Dinamis SMA. Jurnal Wahana Pendidikan Fisika. Vol.3 No.2 : 51-61

Adie Perdana, Fengki. 2017. Development of e-module combining science process skills and dynamics motion material to increasing critical thinking skills and improve student learning motivation senior high school Int. J. Sci. Appl. Sci.: Conf. Ser. Vol. 1 No. 1 (2017) 45-54

Edhi Winatha, Komang. 2018. The Usage Effectivity Of Project-Based Interactive E-Module In Improving Students' Achievement. Jurnal Pendidikan Teknologi dan Kejuruan, Vol. 24, No. 2, October 2018, 198-202

Syamsurizal.2015. Pengembangan E-Modul Berbasis Keterampilan Proses Sains Pada Materi Kesetimbangan Kimia Untuk Tingkat SMA. Prosiding SEMIRATA 2015 bidang MIPA BKS-PTN Barat Universitas Tanjungpura, Pontianak Hal. 655 - 661

Bybee, R. W. 2013. The case for STEM education: Challenges and opportunity. Arlington, VI: National Science Teachers Association (NSTA) Press.

Rais. 2010. PROJECT-BASED LEARNING: Inovasi Pembelajaran yang Berorientasi Soft skills. (Online) (http://digilib.unm.ac.id/files/disk1/1/universitas\%20negeri\%20 makassar-digilib-unmdrmuhraiss-20-1-makalah-a.pdf.), diakses pada 10 September 2019

Stohlmann, M., Moore, T.J., \& Roehrig, G.H. 2012. Considerations for teaching integrated STEM education. Journal of Pre-College Engineering Education Research (J-PEER), II(1): 28-34 